\title{
La creación de productos comunicativos audiovisuales. Una mirada al audiovisual ecuatoriano
}

\section{The creation of audiovisual communication products. A look at the Ecuadorian audiovisual}

Carlos Ernesto Gavilondo Rodríguez

Juan Manuel Palacio Ospina

Universidad Politécnica Salesiana, Ecuador

Autor para correspondencia: gavilondocarlos@gmail.com; jplacioso@est.ups.edu.ec

Fecha de recepción: 23 de Agosto de 2016 - Fecha de aceptación: 26 de Septiembre de 2016

Resumen: Para la elaboración del artículo se revisó bibliografía actualizada sobre la temática que, sin dudas, sirvió de apoyo para la sistematización y/o recopilación de saberes en esta área del conocimiento. Para ser consecuentes con el objetivo general que se distingue por: analizar las concepciones teóricas que sustentan la construcción de productos comunicativos audiovisuales. Se estipularon, como objetivos específicos, los siguientes: estudiar las teorías y modelos de la comunicación que han servido como punto de partida a los estudios teóricos en Latinoamérica, definir y conceptualizar el proceso de construcción del producto comunicativo y, en especial, en el área del audiovisual. La pregunta de investigación se formula desde el siguiente cuestionamiento: cuáles han sido los principales referentes teóricos para la construcción de productos comunicativos audiovisuales en Latinoamérica. Para sustentar, con mayor profundidad, el desarrollo de la investigación se plantea una segunda pregunta de investigación que se reconoce como: cuál es la metodología a seguir para la construcción de productos comunicativos audiovisuales. Revisada y aprobada la propuesta, por la unidad especial de titulación de la universidad, habiendo recopilado la bibliografía necesaria y con la convicción de la utilidad de la investigación comenzó el trabajo. De esta manera, el alcance de la investigación, conseguiría un acercamiento a las concepciones teóricas que sustentan la construcción de productos comunicativos audiovisuales. Se espera que los resultados de la investigación puedan servir como referente teórico para futuros artículos relacionados con el tema y como base de conocimiento para estudiantes de Comunicación Social

Palabras claves: comunicación; audiovisual; Ecuador

Abstract: For the preparation of the article updated bibliography on the subject that undoubtedly served as support for systemization and / or compilation of knowledge in this area of knowledge it was revised. To be consistent with the overall objective distinguished by: analyze the theoretical concepts underpinning the construction of audiovisual communication products. Were stipulated, as specific objectives, the following: to study the theories and models of communication that have served as a starting point for theoretical studies in Latin America, define and conceptualize the process of building the communicative product and, especially, in the area audiovisual. The research question is formulated from the following question: what have been the main theoretical construction of audiovisual communication products in Latin America referents. To support, further, the development of research raises a second question research that is recognized as: what 
is the methodology for the construction of audiovisual communication products. Reviewed and approved the proposal by the special unit of the university degree, having collected the necessary literature and convinced of the usefulness of research began work. Thus, the scope of the investigation, get an approach to the theoretical concepts underpinning the construction of audiovisual communication products. It is expected that research results can serve as a theoretical reference for future articles related to the subject and as a knowledge base for students of Social Communication

Key words: communication; audiovisual; Ecuador

\section{Introducción}

Los que se han aventurado al estudio y construcción de modelos comunicativos plantean que donde quiera que se produzca un proceso comunicativo este puede ser reducido a modelos. Vale destacar que, tales modificaciones, partirán siempre de la concepción de comunicación de la que se parta, entendiendo este proceso como: transmisión de información, medios de comunicación social, acto de significación o como proceso lingüístico. De manera muy general Pelayo (2010) afirma que "la comunicación es un proceso mediante el cual se transmite información a un destino“ (p. 12). Por su parte, y en este mismo orden, Rodrigo (1989) define que:

Los primeros estudios modernos sobre la comunicación surgieron en los años veinte y treinta y tenían, en común, la preocupación por los medios como influenciadores sociales. El contexto científico, en aquella época propiciaba la concepción del fenómeno de la comunicación como un proceso de estímulo-respuesta (p. 39).

El interés por el estudio de la comunicación como fenómeno social, en el presente, sigue teniendo notable fuerza a la luz de los desarrollos tecnológicos que median. En ese sentido Pelayo (2002) señala que "cuando se habla de comunicación los distintos exponentes y/o representantes están de acuerdo en algo: la comunicación es un proceso que involucra, por lo menos, cuatro componentes básicos que son: un emisor, un mensaje, un canal y un receptor“ (p. 17).

Los productos comunicativos, como parte del proceso de comunicación, son la consecuencia de operaciones sociosemiòticas de la producción e integran características técnicas y estrategias discursivas. Varios autores, en ese sentido, dejan planteado que para la difusión de un producto comunicativo se tiene en cuenta la segmentación de las audiencias y esto, por supuesto, orienta el mensaje. Se puede decir, entonces, que la producción comunicativa establece modelos de discursos, enunciatario y destinatario. En el proceso de investigación se encontraron referentes que plantean lo referido a la antropología audiovisual. En este aspecto se recomienda detenerse en tanto el audiovisual ecuatoriano apela, en la mayoría de sus producciones, a este aspecto que conecta de modo directo con la esencia misma de la antropología sociocultural la cual, según Robles (2012) "pretende vincularse a la orientación pública“ (p. 147). Acerca de los estudios de antropología audiovisual y su reconocimiento en la academia Robles (2012) plantea que:

A pesar de esta utilización de los medios audiovisuales desde un primer momento, la Antropología audiovisual tardaría décadas en encontrar reconocimiento y legitimidad por parte de la academia, de hecho es un objetivo aún por consolidar1. El discurso verbal y escrito es hegemónico y tanto la imagen suspendida (fotografía) como la imagen en 
movimiento (cine) son consideradas como meros complementos menores de la investigación social y del conocimiento científico. No obstante, desde inicios de este siglo, la Antropología audiovisual ha ido ganando reconocimiento como herramienta estratégica de reflexión, intervención social y difusión de la investigación etnográfica. De este modo ha contribuido a conectar el ámbito académico con la sociedad de una forma crecientemente horizontal y participativa.

El audiovisual ecuatoriano, objeto de estudio de la investigación, ha experimentado un lento proceso de expansión tanto industrial como tecnológica en las últimas décadas. En este debate el Dr. Santiago Rubín de Celis Pastor, (Rubin de Celis, 2014) nos deja de manera bien explícita la siguiente reflexión en torno al audiovisual ecuatoriano:

Un progreso cuantitativo y cualitativo evidente del que no es ajena la creación del Consejo Nacional de Cinematografía (CNCINE), órgano que regula y promociona el cine nacional, y la entrada en vigencia de la Ley del Cine de 2006. Así, por ejemplo, frente a los diecisiete filmes de ficción producidos en el amplio lapso 1924-1999, el promedio de largometrajes realizados en el Ecuador desde 2006 alcanza una cifra anual que fluctúa entre los diez y los doce, con éxitos comerciales tan significativos como los de Qué tan lejos (2006) de Tania Hermida - 220.000 espectadores2 -, A tus espaldas (2010) de Tito Jara - 120.000 - o el documental Con mi corazón en Yambo (2011) de Fernanda Restrepo - 150.000 - , y una presencia cada vez más destacada en festivales y muestras internacionales. Como el país mismo, que atraviesa un proceso de modernización y desarrollo contundente, el cine ecuatoriano vive hoy seguramente su momento álgido (p.33).

En todo este devenir del audiovisual ecuatoriano se pone de manifiesto el papel que juegan, y seguirán jugando, las nuevas tecnologías de la información y la comunicación. Por estos tiempos de ello depende la producción de productos comunicativos aunque destacados autores manifiestan que el desarrollo tecnológico no es sinónimo de excelentes y poderosos modelos comunicativos, o sea, que este desarrollo, no siempre potencia las concepciones teóricas que sustentan la producción de productos comunicativos. Si se reflexiona en lo anterior se coincide con Abancéns (2014) cuando expone "no estamos en una época de cambios. Estamos en un cambio de época de la humanidad. Y aún diría más, estamos en la tercera revolución industrial“ (p. 211). Y continúa afirmando "calma. Todo va muy deprisa y todo va muy despacio. Y calma porque yo de verdad no sé cómo estaríamos sino estuviéramos en esta dichosa crisis que todo lo está trastocando“" (p. 211).

Para el entendimiento de todo este proceso es necesario, además, el estudio de las mediaciones. En ese sentido Acosta (2015) señala que muchos pensadores (tanto autores latinoamericanos como del llamado Primer Mundo) sustentan que la Sociedad de la Información requiere establecer matices a nivel macro, meso y micro, pero subrayan que la subversión espiritual de la vida cotidiana que ésta implica, tiene de positivo la activación de los seres humanos (p. 5).

Se puede afirmar, entonces, que estamos en presencia de un gran cambio sociológico emanado por las nuevas tecnologías. Vale destacar, en este sentido, a George Yúdice (2006), 
citado en Acosta (2015), cuando evaluando a la cultura como un recurso de la era global expone que:

La culturización de la llamada nueva economía a partir del trabajo cultural e intelectual - o mejor aún, de la expropiación del valor de la cultura y del trabajo intelectualse ha convertido, con la ayuda de las nuevas comunicaciones y de la tecnología informática, en la base de una nueva división del trabajo (p. 4).

La investigación arroja como uno de sus resultados, en total acuerdo con Abancéns (2014), que "la cinematografía ecuatoriana está firmemente ligada al cine de no-ficción” (p. 35). Por eso deja definido que:

Una tradición fértil, en el caso de Ecuador, desde sus orígenes: ya en la década de los años 20 destacan noticiarios y series informativas como Gráficos del Ecuador (1921) y Los funerales del general Eloy Alfaro (1921), "la más impresionante y bella de las películas cinematográficas nacionales" según la publicidad de la época, exhibidas por la compañía guayaquileña Ambos Mundos, productora y distribuidora primigenia en el Ecuador, así como los trabajos pioneros de José Ignacio Bucheli - Las festividades del Centenario de la Independencia (1922), filmada íntegramente en Quito; Sobre el Oriente ecuatoriano (1926), "copiando del natural la vida de sus pobladores y sus extraños quehaceres"- y del sacerdote italiano Carlos Crespi, precursor del cine en Cuenca, autor de Los invencibles shuaras del Alto Amazonas (1926), una serie de vistas de la vida diaria de las comunidades indígenas del este del país. Para el período 1911-1990, los cortometrajes y los documentales constituyen la parte más significativa de la producción ecuatoriana. Sin intención exhaustiva, 4 un breve repaso a determinados contextos del cine de no-ficción en el Ecuador puede ayudarnos, en paralelo, a identificar las continuidades y las rupturas de propuestas contemporáneas respecto al pasado (p. 35-36).

Desde los años 2000 el audiovisual ecuatoriano se centró, al decir de Abancéns (2014), en la revisión de algunas de las páginas de la historia y esto ha llevado, como bien el resume, a producciones que han marcado la existencia de un audiovisual de contenido en Ecuador. En ese sentido, Abancéns (2014), cita obras que destacan al audioviual ecuatoriano en Latinoamérica tales como: Alfredo vive Carajo! (2007) de Isabel Dávalos, recuento del movimiento guerrillero del mismo nombre, activo entre los años 1983 y 1988, y Con mi corazón en el Yambo, galardonada con numerosos premios internacionales, que se apoya en una vena testimonial de rica praxis en América Latina (de la obra de documentalistas "clásicos" como Santiago Álvarez o Patricio Guzmán al nuevo cine-activismo político realizado por colectivos de producción audiovisual periféricos), innovando al tiempo en sus modelos de referencia. Además, el destacado rendimiento comercial de ambas, sobre todo el de ésta última, el documental más visto de la historia del cine ecuatoriano, demuestra la cada vez mayor viabilidad económica de la producción de cine documental en una industria aún pequeña como la ecuatoriana (p. 38).

El acontecer socio-político del Ecuador ha potenciado el reinvento constante del audiovisual etnográfico teniendo, como temas demandantes de producción, las costumbres y la cultura indígena. Todo esto queda necesaria y pertinentemente explícito en Abancéns (2014) cuando, realizando un recuento de la cinematografía ecuatoriana reflexiona y señala: 
El cine indigenista, muy presente también en otros países como Perú, en la obra de directores como Manuel Chambi, Eulogio Nishiyama, Luis Figueroa y César Villanueva, o Bolivia con Jorge Sanjinés, quien filmó en el Ecuador Llocsi caimanta (Fuera de aquí, 1981), ha sido en Ecuador el campo de una dominación racial. A través de esos textos audiovisuales, creando y recreando nociones sobre el otro basadas en su diferencia e inferioridad, se propuso un "ideal" de integración social (como también sucedió en otros países del continente americano) bajo formas racializadas y excluyentes (p. 39).

La investigación, para la redacción del artículo académico, servirá de ejercicio académico para la titulación como Licenciado en Comunicación Social con mención en Producción Audiovisual y Multimedios.

\section{Metodología}

Para la obtención del título de Licenciado en Comunicación Social con mención en Producción Audiovisual y Multimedios se presenta la investigación para la elaboración del artículo académico, como ejercicio de titulación en la carrera de Comunicación Social de la Universidad Politécnica Salesiana, sede Guayaquil, Ecuador. La línea de investigación seleccionada, de la cual se deriva el tema y título para la elaboración del artículo, está reconocida dentro de las líneas de la carrera de Comunicación Social bajo el referente creación de productos comunicativos. Sus fundamentos.

Para la elaboración del artículo se revisó bibliografía actualizada sobre la temática que, sin dudas, sirvió de apoyo para la sistematización y/o recopilación de saberes en esta área del conocimiento.

Para ser consecuentes con el objetivo general que se distingue por: analizar las concepciones teóricas que sustentan la construcción de productos comunicativos audiovisuales. Se estipularon, como objetivos específicos, los siguientes: estudiar las teorías y modelos de la comunicación que han servido como punto de partida a los estudios teóricos en Latinoamérica, definir y conceptualizar el proceso de construcción del producto comunicativo y, en especial, en el área del audiovisual.

La pregunta de investigación se formula desde el siguiente cuestionamiento: cuáles han sido los principales referentes teóricos para la construcción de productos comunicativos audiovisuales en Latinoamérica. Para sustentar, con mayor profundidad, el desarrollo de la investigación se plantea una segunda pregunta de investigación que se reconoce como: cuál es la metodología a seguir para la construcción de productos comunicativos audiovisuales. Revisada y aprobada la propuesta, por la unidad especial de titulación de la universidad, habiendo recopilado la bibliografía necesaria y con la convicción de la utilidad de la investigación comenzó el trabajo. De esta manera, el alcance de la investigación, conseguiría un acercamiento a las concepciones teóricas que sustentan la construcción de productos comunicativos audiovisuales. Se espera que los resultados de la investigación puedan servir como referente teórico para futuros artículos relacionados con el tema y como base de conocimiento para estudiantes de Comunicación Social. 
Para llevar a cabo la investigación y ser consecuentes con los objetivos planteados se determina utilizar el tipo de investigación cualitativa pues, como bien expresa Bernal (2010) "las apropiaciones de métodos de investigación de matriz cualitativa pueden asociarse con el interés por analizar los procesos de producción“ (p.64). Desde el punto de vista metodológico se han diferenciado dos categorías de análisis, estas son: proceso de creación y productos comunicativos audiovisuales. Como técnicas de investigación se emplearon las siguientes: revisión bibliográfica documental, análisis de documentos y el análisis de contenido. La principal técnica empleada hace referencia a la revisión bibliográfica documental en tanto el estudio se define como eminentemente teórico. Esta técnica permitió realizar una revisión histórica y analítica. El análisis de contenido ocupó, también, un lugar importante en la investigación en tanto, desde su epistemología, se reconoce al decir de Piñuel (2002) como:

Conjunto de procedimientos interpretativos de productos comunicativos (mensajes, textos o discursos) que proceden de procesos singulares de comunicación previamente registrados, y que, basados en técnicas de medida, a veces cuantitativas (estadísticas basadas en el recuento de unidades), a veces cualitativas (lógicas basadas en la combinación de categorías) tienen por objeto elaborar y procesar datos relevantes sobre las condiciones mismas en que se han producido aquellos textos, o sobre las condiciones que puedan darse para su empleo posterior (p. 2).

El análisis de contenido aportó la información necesaria para la comprensión de que el audiovisual ecuatoriano se ha permeado de temas referidos a lo etnográfico. Por ello coincidimos con Piñuel (2002 cuando plantea que:

El análisis de contenido no debe perseguir otro objetivo que el de lograr la emergencia de aquel sentido latente que procede de las prácticas sociales y cognitivas que instrumentalmente recurren a la comunicación para facilitar la interacción que subyace a los actos comunicativos concretos y subtiende la superficie material del texto (p. 4).

Como el objeto de estudio puede relacionarse con interpretaciones que se realicen a partir de la experiencia del ser humano se decide optar por el enfoque cualitativo lo cualitativo considerándolo el más oportuno. En este sentido se coincide con la Dra. Saladrigas (2005) cuando expone que "la teoría se construye en el mismo proceso de investigación, en medio de una continua interpelación entre el análisis y la recogida de datos" (p. 8). Por lo anterior expuesto se utiliza, como método de investigación, la Teoría Fundada mediante el cual, al decir de Bernal (2010), " permite que la información obtenida sea fundamentada y conceptualizada a la luz de determinadas perspectivas teóricas" (p. 34).

En estudios y reflexiones sobre esta teoría Pandit (1996) define a la Teoría Fundada como:

Una forma de construcción del conocimiento mediante el empleo de procesos inductivos, a partir de la comparación de los datos con la teoría y aporta sólidos criterios para alcanzar una adecuada validación de los estudios que emplean ese método. Entre ellos la necesidad de la definición de tres elementos básicos: conceptos, categorías y proposiciones (p. 23).

La investigación no se asienta, solamente, en sapiencias inductivas sino, también, en el análisis bibliográfico y su aplicación a las situaciones objeto de investigación. Haig (1995), (como 
se citó en Acosta-Damas, 2009) define que "la Teoría Fundada es la constante comparación y el muestreo teórico de los procedimientos de codificación de elementos“" (p. 62).

\section{Técnicas de investigación:}

Análisis bibliográfico o documental: se empleó para el estudio y sistematización de las fuentes teóricas de la disciplina. Forma parte del proceso inicial de la investigación la búsqueda y análisis crítico de textos relacionados con temas de producción audiovisual, lenguaje audiovisual, cine de ficción y no ficción, antropología del relato audiovisual, análisis de contenidos y procesos de recepción de manera, en algunos casos, general, y en otras específicas tomando en cuenta los diferentes enfoques teórico - metodológicos de los que parten sus autores.

Triangulación: se empleó para lograr el cruce dialéctico de toda la información pertinente al objeto de estudio surgida en la investigación empírica y teórica.

Recolección de datos: se empleó para obtener suficiente información y se aplicaron los métodos de recolección de datos que más convinieron a la naturaleza cualitativa del estudio.

Análisis de contenido: se empleó teniendo en cuenta los procedimientos que lo caracterizan pero sin adentrarse en las combinaciones que se pueden dar. De las tipologías de análisis de contenido reconocidas se emplearon las de carácter exploratorio y descriptivos. Se apoyó la investigación en este tipo de análisis teniendo en cuenta lo que plantea Piñuel (2002) cuando esboza que:

Los análisis exploratorios sólo tienen por objeto una aproximación al diseño definitivo de una investigación en la que el análisis de contenido sea una técnica elegida para elaborar, registrar y tratar datos sobre documentos (p. 8).

Y refiriéndose a los análisis de tipo descriptivos plantea que:

Los análisis descriptivos tienen por objeto, en un marco de estudio dado, la simple identificación y catalogación de la realidad empírica de los textos o documentos, mediante la definición de categorías o clases de sus elementos. Como uno de los análisis de contenido descriptivos más específico puede citarse el análisis documental (o de recuperación de información) con muchas variantes (p. 9).

\section{Resultados}

La investigación propone, desde su concepción, analizar las concepciones teóricas que sustentan la construcción de productos comunicativos audiovisuales dando una mirada al audiovisual ecuatoriano. La revisión bibliográfica arrojó que no existe mucho material en términos académicos y científicos en este campo o área de investigación por lo que el trabajo, que se concibió puramente teórico, necesitó de un gran tiempo de trabajo, rastreo de información y lectura por parte del investigador. Se evidencia, como parte de los resultados, la vigencia del pensamiento crítico de Jesús Martín Barbero en su reconocida "Teoría de las mediaciones" citado en Pineda de Alcàzar (2001) de la siguiente manera: 
El movimiento crítico que se originó a partir de Martín-Barbero llevo a los estudios de recepción latinoamericanos a establecer distancias fundamentales con los enfoques funcionalistas de la escuela norteamericana, con los enfoques semióticos e, incluso, con los de la escuela de Frankfurt. En esa separación se acerca, al sujeto, a su mundo de vida con su contexto real y con su entorno cotidiano, abordando los problemas de la cultura popular en su relación con la cultura masiva (p. 23).

Se aprecia y entiende que la tradición documentalista en América Latina en general, y en Ecuador, se relaciona a un cine de no ficción referido a temáticas de intensión social y política. Esta inclinación del cine ecuatoriano por esas temáticas apunta a la definición que compartimos con Rubin de Celis (2014) cuando plantea que "esta faceta radicalizada del documental latinoamericano podría resumirse sintéticamente como la expresión cinematográfica de una resistencia política“ (p. 36). En ese sentido se constató que, para la realización de este tipo de obra, urge mucho prestar atención a aspectos estéticos y de producción pero, además, tener en cuenta cómo todos estos factores influyen en las intenciones de la obra teniendo en cuenta su carácter eminentemente social y político.

Entrevistas realizadas a realizadores del género ficción y no ficción, así como a estudiantes que se forman en las carreras de comunicación social y medios audiovisuales, arrojaron datos significativos que potencian nuestro punto de partida en tanto, muchos de ellos, coinciden en plantear que la cinematografía ecuatoriana tiende a una intención social. Forma parte de nuestros resultados teóricos el haber podido percatarnos durante este período de investigación que si bien en nuestro país aún no existe una cultura en términos de creación y producción audiovisual ya ese entorno va cambiando. A ese empeño se han sumado diferentes instituciones educativas del país y, requiere un especial énfasis, la Asociación Ecuatoriana de Productores y Comercializadores de Obras Audiovisuales, reconocida por sus siglas ASECOPAC.

Al parecer la última década ha sido decisiva en la vida del audiovisual ecuatoriano. Leyes implantadas promueven la producción audiovisual nacional. En ese sentido Tapia Ruiz, (2015) expone:

El artículo 97 de la Ley Orgánica de Comunicación de Ecuador (LOC) señala que los medios de comunicación audiovisual, de origen nacional, deben destinar de manera progresiva al menos el $60 \%$ de su programación diaria a la difusión de contenidos de producción nacional (parr. 3).

En ese mismo orden se coincide con Adrìan Castro (como se citò en Tapia Ruiz, 2015) cuando deja definido que "hay más trabajo por hacer, ya que todas esas piezas audiovisuales que se pautaban ahora deben ser producidas en el país, eso quiere decir que la producción nacional creció en exigencias y en oportunidades" (parr. 4). Una de las limitantes a la que se enfrenta el realizador audiovisual del Ecuador es la referida al tema del presupuesto. Este tema del presupuesto ha sido analizado y estudiado en funciòn de encotrar variantes màs econòmicas pero sin dejar, a un lado, la calidad. En ese sentido Adrìan Castro (como se citò en Tapia Ruiz, 2015) expresa que "el campo ha crecido, pero hacer producción no es barato. El Gobierno debería apoyar más. Faltan escuelas de cine, incentivos económicos y leyes que regulen el área” (parr. 8). 
Otro componente necesario a tener en cuenta como parte de los resultados y que con total eficacia valida los mismos es, sin dudas, lo planteado por Rubin de Celis (2014) en su estudio acerca del cine documental ecuatoriano contemporàneo cuando realta que:

Un colectivo, coordinado por José Yépez, que, partiendo de los principios del cine directo y de la búsqueda de nuevas formas de documental militante, testimonió (con un metraje total de más de veinte horas) la situación política en el convulso 2005 en la ciudad de Guayaquil: la Marcha Blanca y las manifestaciones populares, la inestabilidad política que asolaba el país y el regreso del ex-presidente Bucaram al Ecuador, tras un asilo político en Panamá. Una praxis que aproxima ésta a otras formas de video-activismo en América Latina en la línea de grupos audiovisuales autónomos como los piqueteros argentinos, o al Proyecto de Medios de Comunicación de Chiapas Promedio, Imágenes en Movimiento y otros colectivos relacionados con el Ejército Zapatista de Liberación Nacional (EZLN), equivalentes contemporáneos de los importantísimos Grupo Cine Liberación y Grupo Cine de la Base (p. 37).

Otro indicador es lo que plantea el periodista y realizador colombiano Andrés Buitrago (como se citó en Tapia Ruiz, 2015) cuando expresa que “la formación de los nuevos profesionales del área y la mentalidad de los jóvenes son un atenuante para el desarrollo nacional“" (parr. 10). En las últimas décadas el cine indigenista se ha desplegado hacia dos direcciones importantes: la defensa de los derechos de los pueblos indígenas y el movimiento ecologista. Al decir de Rubin de Celis (2014) el ejemplo más significativo de esto es el filme Soy defensor de la selva del realizador Eriberto Gualinga (2005) y continúa acotando que:

La película fue ganadora del premio Anaconda a los audiovisuales indígenas entregado ese mismo año en La Paz, Bolivia, que toma una postura militante, desde dentro, concienciadora, respecto a la necesidad de proteger la biodiversidad y prevenir el cambio climático, defendiendo a un tiempo su hábitat natural. Un film en el que, como ha señalado acertadamente María Luisa Ortega (2011), autorepresentación y autogestión indígenas están firmemente conectadas (p. 41).

La investigación realizada y los métodos y técnicas empleados ratifican lo planteado por Rubin de Celis (2014) cuando plantea:

El imaginario colectivo ha identificado comúnmente, de forma un tanto simplista, el cine documental con un cine de la memoria. Sin embargo el cine de no ficción contemporáneo en Ecuador no se limita, evidentemente, a dichas coordenadas temáticas heredadas del pasado (aunque sean expuestas bajo formas nuevas); vigorizado por la modernización del país, se abre coincidiendo con la ebullición del cine de lo real a nivel global planetario, a un continuo desarrollo de fronteras y horizontes hasta ahora desconocidos (p. 41).

Según criterios de los realizadores encuestados este periodo del audiovisual ecuatoriano se caracteriza, fundamentalmente, por una gran diversidad temática y de nuevos enfoques. Se ha llegado, por criterios de Rubin de Celis (2014), a un estadio que pudiera delimitarse como: 
Un momento histórico en el que Ecuador posee una confianza infinita en las imágenes y los sonidos que hablen sobre él, en sus historias y mitos propios, en unas imágenes sobre el pasado, sí, devolviéndole su historia reciente como la herencia más preciada, pero también sobre el presente y lo futuro. Este estallido - porque no cabe calificarlo de otro modo- parte de una concepción de sí mismo por parte del cine de no ficción como de una "investigación crítica de un mundo liberado y sin fronteras al que hace toda clase de preguntas por medios que se han vuelto complejos"7, y también sobre una ampliación del horizonte de lo que puede o no convertirse en un hecho, más que cinematográfico, cinematografiable (p. 41-42).

\section{Conclusiones}

Luego de realizar un repaso de todos los hitos estudiados para la redacción del artículo académico y los resultados se puede afirmar que la calidad de la producción audiovisual, en Ecuador, se ha perfeccionado y va por un muy buen camino. Las temáticas más abordadas, en la actualidad se refieren al mundo indigenista y al tratamiento de la ecología. Se considera, a partir de la experiencia vivida en esta investigación, que se debe potenciar la producción científica en temáticas referidas al cine de ficción y no ficción ecuatoriano. Mucha información alegórica a este tema aparece como parte de escritos de periódicos nacionales aunque, por supuesto, existen obras audiovisuales que se refieren al tema. Un ejemplo a citar es la obra "Màs allá del Moll" reconocida como producción nacional. Las instituciones escolares u docentes deben potenciar el estudio de la cinematografía universal pero hacer hincapié, además, en la cinematografía ecuatoriana. De esta manera puede lograrse la motivación necesaria para el aumento de la producción nacional en términos de creación audiovisual y producción científica. Las nuevas generaciones, al decir de Tapia Ruiz (2015) "deben adaptarse a los cambios y sacarles provecho para conseguir resultados de impacto en materia audiovisual, con el objetivo de competir en el mercado internacional" (parr. 20). Se espera que la investigación motive la reflexión en torno al audiovisual ecuatoriano y su visión futura.

\section{Bibliografía}

Abancéns, J. (2014). Cambios sociológicos producidos por las nuevas tecnologías. adComunica. Revista de Estrategias, Tendencias e Innovación en Comunicación.(8), 209-211. doi:http://dx.doi.org/10.6035/2174-0992.2014.8.12

Acosta Damas, M. (2009). Tesis de Doctorado. La Entrevista En El Sistema Informativo De La Televisión Cubana: retos en la sociedad contemporánea. La Habana, La Habana, Cuba: Universidad de La Habana. Facultad de Comunicación Social. Recuperado el 22 de Agosto de 2015

Acosta, M. (Diciembre de 2015). Discurso informativo audiovisual y mediaciones: Una propuesta conceptual contrahegemónica. Razón y Palabra(92), 1-31. Recuperado el 26 de Febrero de 2016, de www.razonypalabra.org.mx 
Almenara, J. C. (15 de Junio de 2002). La introducción del vídeo como instrumento de conocimiento en la enseñanza universitaria. Sevilla, Sevilla, España. Recuperado el 10 de Agosto de 2015, de http://tecnologiaedu.us.es/revistaslibros/Artg-ice2.html

Andreu-Sánchez, C., \& Martín-Pascual, M. (2014). La educación audiovisual y la creación de prosumidores medíaticos. Estudio de caso. adComunica. Revista de Estrategias, Tendencias e Innovación en Comunicación.(7), 131-147. Recuperado el 2 de Febrero de 2015

Aparicio, A. (2011). Recuperado el 23 de Agosto de 2015, de https://www.uam.es/personal_pdi/stmaria/jmurillo/Met_Inves_Avan/Presentaciones/Cues tionario_\%28trab\%29.pdf

Ballesteros, B. (Febero-Abril de 2011). Comunicación y cambio social. Razón y Palabra(75). Recuperado el 19 de Agosto de 2015

Berlo, D. (2002). El proceso de comunicaciòn. Introducciòn a la teorìa y la pràctica. Madrid: El Ateneo.

Bernal, C. A. (2010). Metodología de la investigación. Bogota: Pearson.

Cabrero, J. (1989). Tecnología educativa: utilización didáctica del video. Barcelona.: PPU. Recuperado el 28 de Septiembre de 2015

Calvo, E. (Junio de 2011). Información audiovisual, multimedia y educación. 10. Granada., España.: Etc@net. Recuperado el 22 de Septiembre de 2015, de http://www.ugr.es/ sevimeco/revistaeticanet/index.htm

Canet., F. (2009). Narrativa audiovisual: estrategias y recursos. Madrid: Sìntesis.

Covadonga de la Iglesia, M. (2012). La identificación de factores en el desarrollo de los estudiantes universitarios. Un estudio exploratorio. Revista Complutense de Educación., 23(1), 207 240. doi:http://dx.doi.org/10.5209/rev_RCED.2012.v23.n1.39110

Cuervo Sánchez, S., \& Medrano Samaniego, C. (Junio de 2013). Alfabetizar en los medios de comunicación: más allá del desarrollo de competencias. Teor. Educ., 2(25), 111-131. Recuperado el 23 de Agosto de 2015

Duch, L. C. (s.f.). Un ser de mediaciones: antropologìa de la comunicaciòn. 2011.

Ezquerra, Á. (2010). Desarrollo audiovisual de contenidos científico-educativos. Enseñanza de las ciencias., 28(3), 353-366. Recuperado el 19 de Julio de 2015

Ezquerra, Á. (2010). Desarrollo audiovisual de contenidos científico-educatvos. Enseñanza de las ciencias, 28(3), 353-366. Recuperado el 22 de Julio de 2015 
Fernández, M. C. (1997). Influencia del montaje en el lenguaje audiovisual. Madrid.: Libertarias.

Medrano Samaniego, C. (2006). El poder educativo de la televisión. Revista de psicodidáctica, 11(1), 93-108.

Morales, F. (2013). Montaje audiovisual: teoría, técnica y métodos de control. UOC.

Muñoz-Alonso, A. (2001). Estructura y ética de los medios de comunicación. III Congreso "Católicos y vida pública“., (págs. 1-15). San Pablo-Ceu. Recuperado el 19 de Marzo de 2015

Pandit, N. (Diciembre de 1996). "La Creación de la teoría: una aplicación reciente del método puesto a tierra de la teoría". Recuperado el 3 de Agosto de 2015, de http://www.nova.edu

Pelayo, N. (2010). Lenguaje y comunicaciòn. Colecciòn Minerva.

Perona., A. M. (2010). Ensayo sobre video, documental y cine. Còrdova: Brujas.

Pineda de Alcàzar, M. (10 de Octubre de 2001). Las teorìas clàsicas de la comunicaciòn: balance de sus aportes y limitaciones a la luz del siglo XXI. Opciòn(36), 11-29. Recuperado el 17 de Febrero de 2016

Piñuel, J. L. (2002). Epistemología, metodología y técnicas del análisis de contenido. Estudios de Sociolingüística, 3(1), 1-42. Recuperado el 5 de Marzo de 2015

Portal, R., \& otros, y. (2008). Comunicación para el desarrollo: selección de lecturas. La Habana, La Habana, Cuba: Editorial Félix Varela. Recuperado el 15 de Agosto de 2015, de http://www.ebrary.com

Prieto Castillo, D. (2006). El interaprendizaje como clave de la educomunicación en mediaciones. Universidad Minuto de Dios(6). Recuperado el 22 de Julio de 2015

Ramos, J. L. (2002). ¿Qué es el vídeo educativo? Madrid, Madrid, España.

Robles, J. (Septiembre de 2012). El lugar de la Antropología audiovisual: metodología participativa y espacios profesionales. Íconos. Revista de Ciencias Sociales.(44), 147-162. Recuperado el 23 de Enero de 2015

Rodiles, A., \& Viel, M. (Marzo de 2016). Comunicación Universitaria. Pautas para su gestión desde el contexto de la Educación. Razón y Palabra(92). Recuperado el 10 de Abril de 2016

Rubin de Celis, S. (3 de Septiembre de 2014). El cine documental ecuatoriano contemporáneo. Tradiciones, horizontes y rupturas. Recuperado el 18 de Marzo de 2016, de Universidad Técnica de Ambato, Facultad de Jurisprudencia y Ciencias Sociales.: www.doc.ubi.pt 
Saladrigas Medina, H. (2005). Comunicación organizacional: Matrices teóricas y enfoques comunicativos. Revista Latina de Comunicación Social. Recuperado el 22 de Agosto de 2015, de http://www.ull.es/publicaciones/latina/200540saladrigas.htm

Sancho, J., Vilches, A., \& Gil, D. (Septiembre de 2010). Los documentales cientìficos como instrumentos de educaciòn para la sostenibilidad. Eureka, 7(3), 667-681. Recuperado el 23 de Agosto de 2015, de http://www.redalyc.org/articulo.oa?id=92017191007

Sandoval, T. (Julio de 1998). Entrevista a "Mariano Cebrian comenta los últimos y los próximos cambios en comunicación audiovisual". Revista Latina de Comunicación Social.(7). Obtenido de http://www.ull.es/publicaciones/latina/a/61ent.htm

Tapia Ruiz, A. (29 de Marzo de 2015). Producción audiovisual, ¿es el momento de Ecuador?. El Telègrafo. Recuperado el 22 de Febrero de 2016, de http://www.eltelegrafo.com.ec/noticias/guayaquil/10/produccion-audiovisual-es-elmomento-de-ecuador

Tostado, V. (1999). Manual de producción de video: un enfoque integral. Alhambra.

Wigodski, J. (14 de Julio de 2010). Metodología del investigación. Recuperado el 19 de Julio de 2015, de http://metodologiaeninvestigacion.blogspot.com/2010/07/poblacion-ymuestra.html 